\title{
Features of the Filum Terminale in Tethered Cord Syndrome with Focus on Pathology
}

\author{
Jungbo Sim,, Youngbo Shim, ${ }^{2}$ Kyung Hyun Kim, ${ }^{2}$ Seung-Ki Kim, ${ }^{2}$ Ji Yeoun Lee ${ }^{2,3}$ \\ Department of Neurosurgery, Seoul National University Hospital, Seoul, Korea \\ Division of Pediatric Neurosurgery, ${ }^{2}$ Seoul National University Children's Hospital, Seoul, Korea \\ Department of Anatomy and Cell Biology, ${ }^{3}$ Seoul National University College of Medicine, Seoul, Korea
}

Objective : Filum transection is one of the most commonly performed operative procedure in pediatric neurosurgery. However, the clinical and pathological features as well as the surgical indication are not well-established. This study aimed to analyze the characteristics of patients who underwent transection of the filum during the last 10 years in a single institute.

Methods : A total of 82 patients underwent transection of the filum during the period. As a general rule, we performed the transection in patients who are symptomatic or have abnormality in the urologic or neuromuscular evaluations. There were exceptions as asymptomatic patients who only fit the definition of thickened filum (width greater than $2.0 \mathrm{~mm}$ or conus level below $\mathrm{L} 3$ vertebral body) were operated by parent's wish or surgeon's preference according to radiological findings, etc.

Results : Seventy-six out of 82 patients had fibrous tissue in the pathologic specimen of filum. Interestingly, patients who had glial cells were more correlated with no preoperative syrinx, and no progression of syrinx even for those who did have syrinx initially. Also, larger percentage of symptomatic patients had peripheral nerve twigs than asymptomatic patients. No difference in conus level or thickness of filum was found between patients with or without preoperative syrinx. Significantly more patients with syrinx (56\%) were chosen to be operated without any symptom or abnormality in study i.e., solely based on radiological findings than those without syrinx (21\%). The surgical outcome for syrinx was favorable, as all but one patient had either improved or static syrinx. The exceptional case had increase in size due to the upward displacement of the proximal end of the cut filum.

Conclusion : This study evaluated the pathological, clinical, radiological features of patients who underwent transection of the filum. Interesting correlations between pathological findings and clinical features were found. Excellent outcome regarding preoperative syrinx was also shown.

Key Words : Filum terminale · Tethered cord syndrome · Syringomyelia · Pathology.

\section{INTRODUCTION}

Transection of the filum terminale is one of the most common operations in pediatric neurosurgery practice ${ }^{7,11}$. It may be performed as part of an untethering operation for a more profound type of spinal dysraphism such as lumbosacral lipoma, split cord malformation, etc. Filum transection is also performed solitarily in cases of tethered cord syndrome sus-

- Received : August 4, 2020 •Revised : September 6, 2020 •Accepted : September 7, 2020

- Address for reprints : Ji Yeoun Lee

Department of Anatomy and Cell Biology, Seoul National University College of Medicine, 103 Daehak-ro, Jongno-gu, Seoul 03080, Korea

Tel : +82-2-740-8205, Fax : +82-2-749-3485, E-mail : ddang1@snu.ac.kr, ORCID : http://orcid.org/0000-0003-0464-7605

This is an Open Access article distributed under the terms of the Creative Commons Attribution Non-Commercial License (http://creativecommons.org/licenses/by-nc/4.0) which permits unrestricted non-commercial use, distribution, and reproduction in any medium, provided the original work is properly cited. 
pected to be caused by thick filum, fatty filum, low-lying conus, or even some cases with normal image findings ${ }^{1)}$. A thickness of $2 \mathrm{~mm}$ or greater is defined as thick filum and low-lying conus is noted in cases where the location of the conus is at or below the L3 vertebral body ${ }^{3,13)}$. Although these cut-off values are widely accepted, there are still variations between the clinical applications of individual surgeons or institutions ${ }^{7}$.

The degree of variation, hence the controversy is even greater in the indication of the transection of filum. Also most of the knowledge is based on the opinion of experts or case series with usually no control group to provide evidence on the effectiveness of surgical intervention in different subjects ${ }^{4,11}$. In fact, a recent study in United States covered the incidence and perioperative features of patients who underwent filum transection operation using a nation-wide database to assess a diagnostic algorithm ${ }^{7}$. The authors showed that patients with comorbidities or an associated syrinx showed a higher chance of untethering procedures for "tethered fibrofatty filum terminale". Despite the shortage of detailed clinical information due to the nature of the study based on national database, the results support the 'variation' of clinical implications regarding the cord tethering related to thickened or fatty filum.

This study reviewed the clinical, radiological, and pathological features of the filum terminale in patients who underwent transection of the filum suspected with tethered cord syndrome. The relation between the conus level, syrinx, clinical characteristics, and pathological features was evaluated.

\section{MATERIALS AND METHODS}

This retrospective study was approved by the Institutional Review Board of Seoul National University Hospital.

Retrospective review of patients who underwent transection of the filum during June 2009 to June 2019 was done. Data including age, sex, clinical symptoms, radiological features, electromyography (EMG) data, urodynamic study (UDS) results (if available), pathological result, postoperative symptom and radiologic outcome were collected. Radiologic features of conus level, thickness of filum, syringomyelia, evidence of 'fatty' filum were assessed. Patients with no other pathology of the spinal dysraphism were only included. Therefore, patients with caudal lipoma or limited dorsal myeloschisis were all excluded.

Preventive surgery is not recommended for 'asymptomatic' thick or fatty filum in our institute. Surgery is recommended in patients with symptoms such as urinary tract infection (UTI) due to neurogenic bladder or foot deformity. Surgical transection is also performed when abnormalities on the EMG and/or UDS are detected. Preventive surgery is also performed on parent's strong demand. Preoperative EMG and UDS were performed in some cases. EMG and UDS were performed as previously described ${ }^{2)}$.

Transection of the filum was performed usually through hemilaminectomy at the level below the conus. Foley insertion is not done, and the patients are usually discharged 3 days after the operation.

Statistical analysis was performed with chi-square test, Fisher's exact test and Student's t-test (R version 4.0.0; R Foundation for Statistical Computing, Vienna, Austria) and significant finding was based on $p$ value of 0.05 or less.

\section{RESULT}

\section{Demographics and descriptive data}

A total of 471 number of patients were operated for spinal dysraphism during the period and 82 patients were included in this study. The median age at operation was 11 months (range, 2 months to 36 years) and there were 43 girls. The conus level was rostral to 3 rd lumbar vertebral body (i.e., L2-3 disc space and above) in 43 (52\%) patients. Twenty-five patients had syrinx preoperatively, of whom 11 showed progression of the syrinx size before the operation. Forty-six patients had radiological evidence of 'fatty' filum, and 27 had thick (larger than $2 \mathrm{~mm}$ ) filum. Regarding the indication for surgical intervention, twenty-two patients (27\%) were asymptomatic but had abnormality only on the EMG and/or UDS. Thirty-four patients (41\%) were symptomatic (neurogenic bladder and/or orthopedic problems). The other 26 patients (32\%) were operated based solely on the radiological features.

Twenty-seven patients (79\%, 27 out of 34) showed symptom improvement. There were no postoperative complications or newly developed symptoms.

Thirty-eight patients showed abnormality in preoperative UDS, while 22 of them were symptomatic. Postoperative UDS was performed on 12 patients with residual urinary symp- 
toms, seven showed improvement. Deterioration in UDS was shown in only one case, but dysuria was decreased.

\section{Pathology}

Seventy-six patients had fibrous tissue in the filum specimen. Sixty-eight patients had adipose tissue components. Thirty-seven patients had glial cells, tested by immunostaining with GFAP, 41 had peripheral nerve twigs. Eight patients had vascular tissue and one patient had muscular tissue. No case of cartilage, bony tissue, ganglion or chronic inflammation was found.

Glial cells were found significantly more frequently in patients without syrinx (31 out of 57, 54\%) than with (six out of $25,24 \%, p=0.021$ ). Also, whereas 50\% (four out of eight) of patients who showed no change in syrinx postoperatively had glial tissue, only $8 \%$ (one out of $13, p=0.047$ ) of patients with decreased syrinx had glial tissue. Symptomatic patients were more likely to have peripheral nerve twigs (22 out of $34,65 \%$ ) than asymptomatic patients (19 out of $48,40 \%, p=0.044$ ).

\section{Syrinx}

Twenty-five patients (30\%) had syrinx before the operation. The level of the conus tip was not different between the syrinx
$(+)$ vs. (-) group. The reason for surgical intervention was different, as more than half (56\%) of the syrinx $(+)$ group were asymptomatic and normal on EMG and UDS, whereas 79\% of the patients without syrinx were either symptomatic or had abnormal results on EMG or UDS ( $p=0.008$, Table 1 ). This may indicate that the additional radiological feature of syrinx seems to drive surgeons and parents to actively intervene with surgical treatment.

Of the 25 patients who had syrinx before the operation, 22 had two or more preoperative images to confirm the preoperative progression of syrinx, and 11 out of 22 showed progression of the syrinx size before the operation. However, no significant difference was found in age, histology, conus level and the presence of fatty change between the groups with and without preoperative progression of syrinx (Table 2).

Twenty-two patients had postoperative follow up images to evaluate the postoperative outcome of the syringes, and 21 patients had either improved $(n=13)$ or no change $(n=8)$ in the size of the syringes. Of the 11 patients who showed preoperative increase in the size of the syrinx, seven showed decrease postoperatively and three showed no change. Transection of the filum had almost always halted the progression of the syrinx (Table 3).

Table 1. Comparison of various features between patients with or without preoperative syrinx

\begin{tabular}{|c|c|c|c|}
\hline & Syrinx (+) $(n=25)$ & Syrinx (-) $(n=57)$ & $p$-value \\
\hline Age (years) & $1.1 \pm 1.1$ & $4.3 \pm 6.9$ & 0.001 \\
\hline \multicolumn{4}{|l|}{ Histology } \\
\hline Fibrous & $24(96.0)$ & $52(91.0)$ & 0.662 \\
\hline Adipose & $19(76.0)$ & $49(86.0)$ & 0.432 \\
\hline Glial & $6(24.0)$ & $31(54.0)$ & 0.021 \\
\hline Peripheral nerve twig & $11(44.0)$ & $30(53.0)$ & 0.631 \\
\hline Conus level & & & 0.210 \\
\hline L2-3 or above & $10(40.0)$ & $33(58.0)$ & \\
\hline Below L3 & $15(60.0)$ & $24(42.0)$ & \\
\hline Fatty change & & & 0.800 \\
\hline$(+)$ & $13(52.0)$ & $33(58.0)$ & \\
\hline$(-)$ & $12(48.0)$ & $24(42.0)$ & \\
\hline Reason for operation & & & 0.008 \\
\hline Symptomatic & $8(32.0)$ & $26(46.0)$ & \\
\hline Asymptomatic with abnormal results on UDS or EMG & $3(12.0)$ & $19(33.0)$ & \\
\hline Asymptomatic & $14(56.0)$ & $12(21.0)$ & \\
\hline
\end{tabular}

Values are presented as mean \pm standard deviation or number (\%). UDS : urodynamic study, EMG : electromyography 
J Korean Neurosurg Soc 64 | July 2021

Table 2. Comparison of various features between patients with or without progression of preoperative syrinx*

\begin{tabular}{|c|c|c|c|}
\hline & $\begin{array}{l}\text { Syrinx preop prog }(+) \\
(n=11)\end{array}$ & $\begin{array}{l}\text { Syrinx preop prog }(-) \\
\qquad(n=14)\end{array}$ & $p$-value \\
\hline Age (years) & $1.1 \pm 0.7$ & $1.2 \pm 1.4$ & 0.829 \\
\hline \multicolumn{4}{|l|}{ Histology } \\
\hline Fibrous & $11(100.0)$ & $13(93.0)$ & 1.000 \\
\hline Adipose & $9(82.0)$ & $10(71.0)$ & 0.661 \\
\hline Glial & $3(27.0)$ & $3(21.0)$ & 1.000 \\
\hline Peripheral nerve twig & $6(55.0)$ & $5(36.0)$ & 0.435 \\
\hline Conus level & & & 0.697 \\
\hline L2-3 or above & $5(45.0)$ & $5(36.0)$ & \\
\hline Below L3 & $6(55.0)$ & $9(64.0)$ & \\
\hline Fatty change & & & 0.695 \\
\hline$(+)$ & $5(45.0)$ & $8(57.0)$ & \\
\hline$(-)$ & $6(55.0)$ & $6(43.0)$ & \\
\hline Reason for operation & & & 0.446 \\
\hline Symptomatic & $2(18.0)$ & $6(43.0)$ & \\
\hline Asymptomatic with abnormal results on UDS or EMG & $2(18.0)$ & $1(7.0)$ & \\
\hline Asymptomatic & $7(64.0)$ & $7(50.0)$ & \\
\hline
\end{tabular}

Values are presented as mean \pm standard deviation or number (\%). *Three patients went under surgery with one preoperative image. UDS : urodynamic study, EMG : electromyography

Table 3. Comparison of various features between patients according to postoperative syrinx outcome

\begin{tabular}{|c|c|c|c|}
\hline & $\begin{array}{l}\text { Postop syrinx static } \\
\qquad(\mathrm{n}=8)\end{array}$ & $\begin{array}{l}\text { Postop syrinx decreased } \\
\qquad(n=13)\end{array}$ & $p$-value \\
\hline Age (years) & $1.9 \pm 1.6$ & $0.7 \pm 0.6$ & 0.052 \\
\hline \multicolumn{4}{|l|}{ Histology } \\
\hline Fibrous & $8(100.0)$ & $12(92.0)$ & 1.000 \\
\hline Adipose & $6(75.0)$ & $10(77.0)$ & 1.000 \\
\hline Glial & $4(50.0)$ & $1(8.0)$ & 0.047 \\
\hline Peripheral nerve twig & $3(37.0)$ & $7(54.0)$ & 0.659 \\
\hline Conus level & & & 0.646 \\
\hline L2-3 or above & $4(50.0)$ & $4(31.0)$ & \\
\hline Below L3 & $4(50.0)$ & $9(69.0)$ & \\
\hline Fatty change & & & 0.659 \\
\hline$(+)$ & $5(63.0)$ & $6(46.0)$ & \\
\hline$(-)$ & $3(37.0)$ & $7(54.0)$ & \\
\hline Reason for operation & & & 0.159 \\
\hline Symptomatic & $3(38.0)$ & $4(31.0)$ & \\
\hline Asymptomatic with abnormal results on UDS or EMG & $2(24.0)$ & $0(0.0)$ & \\
\hline Asymptomatic & $3(38.0)$ & $9(69.0)$ & \\
\hline
\end{tabular}

Values are presented as mean \pm standard deviation or number (\%). UDS : urodynamic study, EMG : electromyography 
The only patient who showed 'increase' of syrinx size after the operation was an 8-month-old girl. Although asymptomatic, her syrinx was increasing in size (Fig. 1A) and her EMG showed abnormal findings. Immediate postoperative course was uneventful. As routine protocol we perform follow up EMG examination 6 months to 1 year after the operation, and her follow up study revealed nearly complete recovery of the previously noted bilateral S1 radiculopathy. Also as a routine follow up, magnetic resonance imaging (MRI) was done at postop 1 year, and the size of the syrinx had increased substantially, with a mass compressing the tip of the conus which was not visible on the immediate postop MRI (Fig. 1B and C). Radiological assumption on the mass was a dermoid cyst, but through careful review of the images in comparison to pre/ postop MRIs, we concluded that the peculiar cystic mass was the curled up proximal end of the fatty filum. No neurologic or urologic deficit was found, so we decided to follow up on the syrinx. The last image (ultrasound) was taken 6 months after the last MRI and a slight decrease in syrinx was noted.

\section{DISCUSSION}

A total of 82 patients underwent transection of the filum in our institute during 10 years. The radiological features varied as the level of the tip of the conus was at or below the L3 vertebral body in 39 patients, fatty filum in 46 patients, and thick filum in 27 patients. Syrinx was found in 25 patients preoperatively and these patients were significantly younger than those without a syrinx $(1.1 \pm 1.1$ years vs. $4.3 \pm 6.9$ years, $p=0.001)$. Pathological analysis revealed the presence of fibrous tissue in $93 \%$ of the patients. The indication for surgery was symptom (UTI or foot deformity), abnormality on EMG and/or UDS, or solely on radiological diagnosis usually due to surgeon's or parent's preference. The presence of syrinx seemed to be a major reason for deciding on surgical intervention for asymptomatic patients without any abnormal results on EMG or UDS.

The presence of fibrous tissues in almost all of the patient is in line with previous reports ${ }^{4,9-11)}$. Even the six patients with negative pathology for fibrous tissue clearly had adipose tissues. Although thin collagen bundles are found in normal fi-
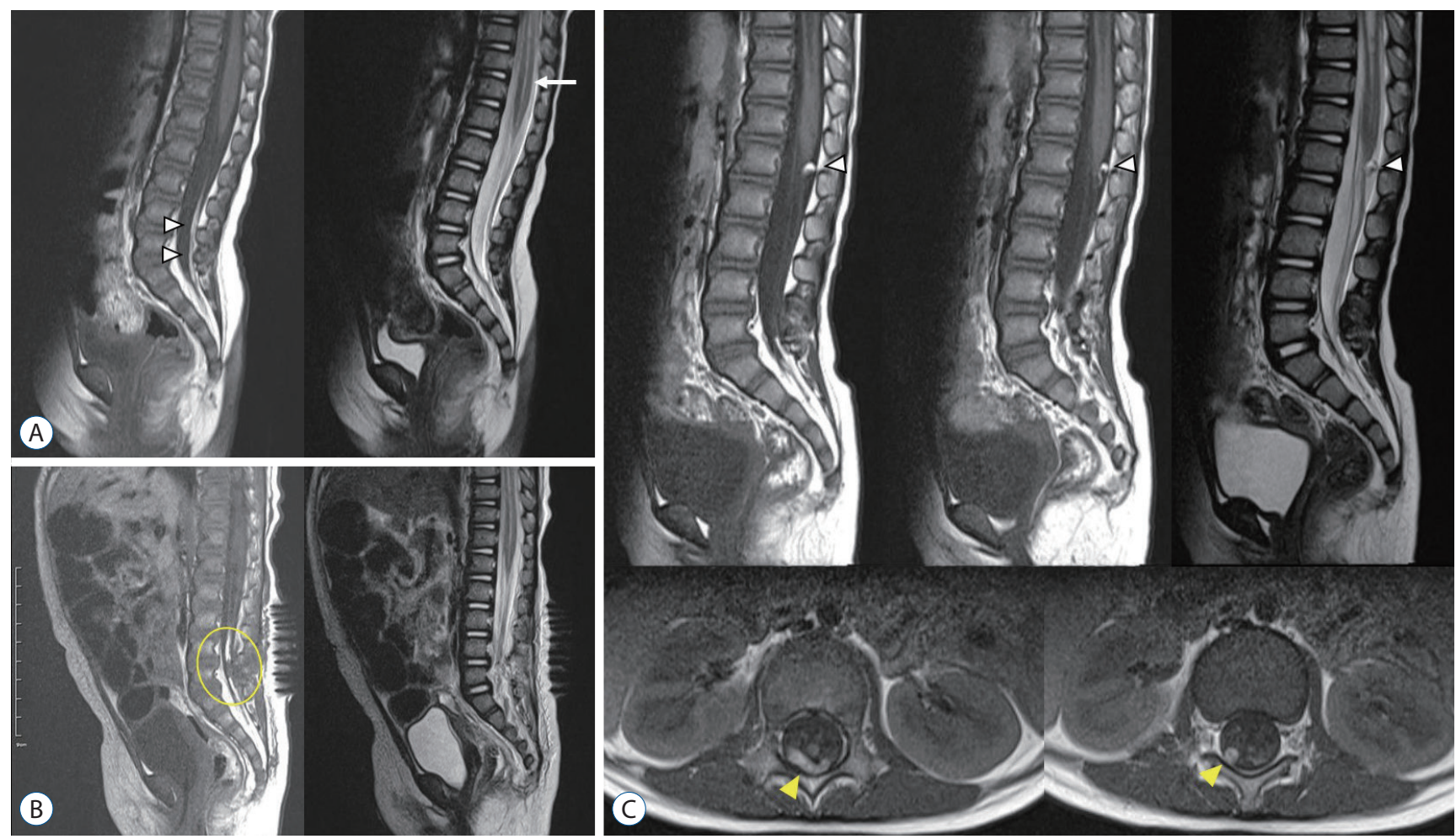

Fig. 1. A : Preoperative MRI showing fatty filum (arrowheads) and syrinx (arrow). B : Immediate postoperative MRI showing cut filum (circle). C : MRI taken 1 year after the operation showing a mass at the dorsal surface of the conus (white arrowheads, high signal intensity on both T2 and T1 images). The axial images reveal that the mass is actually elongated, linear shape (yellow arrowheads) suggesting it is the curled up proximal end of the cut filum. MRI : magnetic resonance imaging. 
lum, thick fibrosis have not been noted in previous studies on the histology of filum. The consistent and well-replicated presence of 'fibrous' tissues in clinical 'thick filum terminale' cases suggest its role in the pathophysiology of cord tethering in the thick or fatty filum cases ${ }^{5,6,8}$. However, despite several studies on the subject, a dominant theory to explain how 'tethering' is caused in these patients is absent.

Two intriguing correlations were found between the pathologic and clinical features. First was the significant correlation with symptom and presence of peripheral nerve twigs. It seems that greater proportion of symptomatic patients (22 out of 34) had peripheral nerve twigs than those who were asymptomatic (19 out of $48, p=0.044$ ). A previous study has reported a similar trend as peripheral nerve twigs on histology was significantly associated with thick filum and abnormal UDS findings ${ }^{11}$. Although the authors of the previous study mentioned the possibility of 'entrapment' of somatic and autonomic nerves innervating the genitourinary system, this seems unlikely considering the normal anatomy of filum where the sacral roots are functionally and physically separated. Although hypothetical, the presence of peripheral nerve twigs may be explained by the fact that the filum is the remnant of the degenerated 'medullary cord' which is originated from 'caudal cell mass' a pluripotent cell mass that is the main player of secondary neurulation. Second was the correlation between the glial tissue and syrinx. It seems that the presence of glial tissue was negatively correlated to syrinx formation or progression. Besides the mechanical theory of syrinx formation, others such as transmedullary bulk flow may be related to the cellular function of cerebrospinal fluid flow in the spinal cord parenchyme, but nothing in detail has been proposed $^{12)}$.

Syringomyelia is an important radiological feature in spinal dysraphism. Enlargement of syrinx implies that cord tethering is present, although exceptions exist. A recent study revealed that syrinx is a significant clinical factor leading to surgical treatment in patients with thick or fatty filum ${ }^{7}$. It was greater than any other parameters such as age or conus level. This study showed that almost all of the patients showed improved or static syrinx size, proving the effectiveness of filum section in such cases. Nonetheless, the abovementioned study suggested, based on the fact that dramatic improvement in syrinx size is not seen in every case, mere presence of mild syrinx may not be an absolute indication for surgery. The quantifica- tion of the postoperative outcome for transection of the filum, as well as the associated syrinx may help define the indication of surgical transection for thick filum ${ }^{12)}$.

This study is limited in that only the patients who were chosen to be operated were enrolled. The enrolled patients were still further limited in that the indication for operation was not strictly applied. Actual comparison of the outcome of 'nonoperated' cases despite fulfilling the definition of thick or fatty filum may add more fulfilling clinical insight.

\section{CONCLUSION}

This study evaluated the pathological, clinical, radiological features of patients who underwent transection of the filum. Interesting correlations between pathological findings and clinical features were found. Excellent outcome regarding preoperative syrinx was also shown.

\section{CONFLICTS OF INTEREST}

No potential conflict of interest relevant to this article was reported.

\section{INFORMED CONSENT}

This type of study does not require informed consent.

\section{AUTHOR CONTRIBUTIONS}

Conceptualization : JS, JYL

Data curation : JS

Formal analysis : JS, YS

Funding acquisition : JYL

Methodology : KHK, JYL

Project administration : JYL, SKK

Visualization : JS, YS

Writing - original draft : JYL 


\section{ORCID}

Jungbo Sim http://orcid.org/0000-0002-2674-1080

Youngbo Shim http://orcid.org/0000-0002-3350-362X

Kyung Hyun Kim http://orcid.org/0000-0002-8238-2043

Seung-Ki Kim http://orcid.org/0000-0002-0039-0083

Ji Yeoun Lee http://orcid.org/0000-0003-0464-7605

\section{- Acknowledgements}

This research was supported by the Bio \& Medical Technology Development Program of the National Research Foundation (NRF) of Korea funded by the Ministry of Science \& ICT (NRF-2018-M3A9H3021707).

\section{References}

1. Blount JP, Elton S : Spinal lipomas. Neurosurg Focus $10: 1-13,2001$

2. Chong S, Lee JY, Kim KH, Shin HI, Kim K, Park K, et al. : Radical excision of lumbosacral lipoma: an early experience of "followers". Childs Nerv Syst 35 : 1591-1597, 2019

3. Cools MJ, Al-Holou WN, Stetler WR Jr, Wilson TJ, Muraszko KM, Ibrahim $M$, et al. : Filum terminale lipomas: imaging prevalence, natural history, and conus position. J Neurosurg Pediatr 13 : 559-567, 2014

4. Cornips EM, Vereijken IM, Beuls EA, Weber JW, Soudant DL, van Rhijn
LW, et al. : Clinical characteristics and surgical outcome in 25 cases of childhood tight filum syndrome. Eur J Paediatr Neurol 16 : 103-117, 2012

5. George TM, Cummings TJ : The immunohistochemical profile of the myelomeningocele placode: is the placode normal? Pediatr Neurosurg 39 : 234-239, 2003

6. Guerra LA, Pike J, Milks J, Barrowman N, Leonard M : Outcome in patients who underwent tethered cord release for occult spinal dysraphism. J Urol 176(4 Pt 2) : 1729-1732, 2006

7. Kashlan ON, Wilkinson DA, Morgenstern H, Khalsa SS, Maher CO : Predictors of surgical treatment in children with tethered fibrofatty filum terminale. J Neurosurg Pediatr 25 : 196-203, 2020

8. Metcalfe PD, Luerssen TG, King SJ, Kaefer M, Meldrum KK, Cain MP, et al. : Treatment of the occult tethered spinal cord for neuropathic bladder: results of sectioning the filum terminale. J Urol 176(4 Pt 2) : 18261829; discussion 1830, 2006

9. Selçuki M, Vatansever S, Inan S, Erdemli E, Bağdatoğlu C, Polat A : Is a filum terminale with a normal appearance really normal? Childs Nerv Syst $19: 3-10,2003$

10. Selden NR, Nixon RR, Skoog SR, Lashley DB : Minimal tethered cord syndrome associated with thickening of the terminal filum. J Neurosurg 105(3 Suppl) : 214-218, 2006

11. Thompson EM, Strong MJ, Warren G, Woltjer RL, Selden NR : Clinical significance of imaging and histological characteristics of filum terminale in tethered cord syndrome. J Neurosurg Pediatr 13 : 255-259, 2014

12. Tsitouras V, Sgouros $S$ : Syringomyelia and tethered cord in children. Childs Nerv Syst 29 : 1625-1634, 2013

13. Yundt KD, Park TS, Kaufman BA : Normal diameter of filum terminale in children: in vivo measurement. Pediatr Neurosurg 27 : 257-259, 1997 